\title{
XRD AND IR INVESTIGATIONS OF SOME COMMERCIAL POLYSTYRENE SAMPLES THERMALLY DEGRADED
}

\author{
CARMEN NICULĂESCU ${ }^{a}$, LOREDANA OLAR ${ }^{\mathrm{b}}$, RĂZVAN STEFAN ${ }^{\mathrm{b}}$, \\ MIHAI TODICA ${ }^{a}$ AND CORNEL-VIOREL POP ${ }^{a, *}$
}

\begin{abstract}
Thermal degradation of commercial polystyrene was investigated by XRD and FT-IR metods. The samples were heated 30 minutes at temperatures $140^{\circ} \mathrm{C}, 200^{\circ} \mathrm{C}, 250^{\circ} \mathrm{C}, 300^{\circ} \mathrm{C}$ and $350^{\circ} \mathrm{C}$ and then brought back to room temperature. XRD investigation denotes structural modification for samples heated above $200^{\circ} \mathrm{C}$. This modification is confirmed by FT-IR measurments. Some vibration bands are affected by thermal degradation at temperatures higher than $200^{\circ} \mathrm{C}$. Both FT-IR and XRD methods reveal modification of microscopic structure of the polystyrene submitted to thermal degradation.
\end{abstract}

Keywords: thermal degradation, commercial polystyrene, FT-IR, XRD

\section{INTRODUCTION}

One of the most important challenges of our days is the destruction and recycling, without pollutant effects, of enormous quantity of polymeric materials produced daily by the humanity. Thermal degradation is the simplest method of destroying, but its use could produce undesired products. The aim of this work is the study of structural changes caused by thermal degradation of one of the most used polymer, the polystyrene. The absorption of energy by heating might cause reversible or irreversible modification of physical and chemical properties of samples by oxidation. Similar studies performed by ESR method on UV-irradiated polystyrene showed possible ionization and breaking of chemical bonds of the polymeric chains, [1]. Gamma irradiation of such materials induces a crystallization effect, as confirmed by NMR, [2].

a Babeş-Bolyai University, Faculty of Physics, 1 M. Kogalniceanu str., RO-400089, ClujNapoca, Romania

b University of Agricultural Science and Veterinary Medicine, Faculty of Veterinary Medicine, 3-5 Calea Mănăștur Street, 400372, Cluj-Napoca, Romania

* Corresponding author: cornel.pop@phys.ubbcluj.ro 


\section{RESULTS AND DISCUSSION}

Polystyrene is a thermoplastic material consisting in unbranched linear macromolecules, obtained by the polymerization of the styrene, with or without a catalyst (Fig. 1).

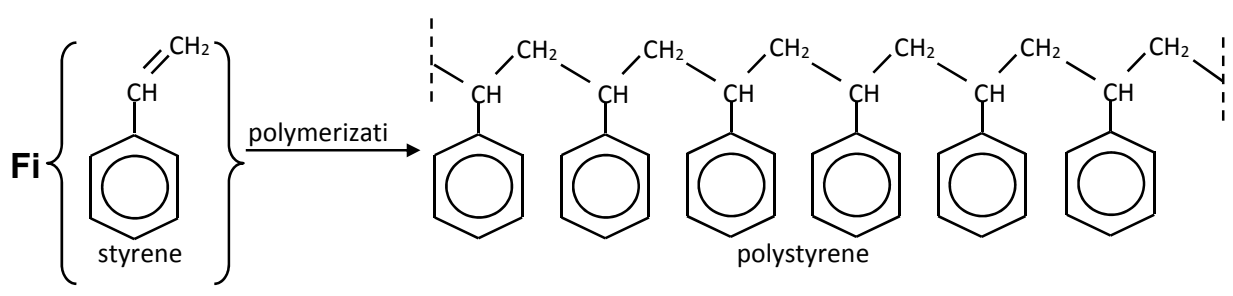

Figure 1. Molecular structure of polystyrene

Generally, these materials are amorphous, but under certain circumstances they can acquire slightly local arrangement. During the synthesis process, it is possible that small quantities of water or solvent to be included in the polymer structure. By heating these residues might be removed by evaporation, which would conduct to a variation of the mass of samples. At high temperatures it is possible that parts of the sample to be oxidized, resulting in the production of chemical compounds different from the initial polymer, which would be later removed by degassing. This process would also have the effect of reducing of the mass of the sample. Our observations have firstly focused on this aspect. The mass variation has been studied in the regard of the temperature. Between $22^{\circ} \mathrm{C}$ and $140^{\circ} \mathrm{C}$ variations of the mass and the color were not observed. Modifications appear above $200^{\circ} \mathrm{C}$. This behavior was associated with the evaporation of water and residual solvents trapped into the polymeric matrices. Above the temperature of $300^{\circ} \mathrm{C}$ the samples become black, and the weight decreases again, (Fig. 2). At this temperature the samples fail to burn and become to degage black smoke, which is responsible for coloring the sample in black. These observations lead us to the supposition that below $140^{\circ} \mathrm{C}$ the samples are stabile, but above this temperature evaporation of the residual water and solvents and oxidation process can occur.

The polymeric materials are known as amorphous materials with very low degree of ordering, [3]. 


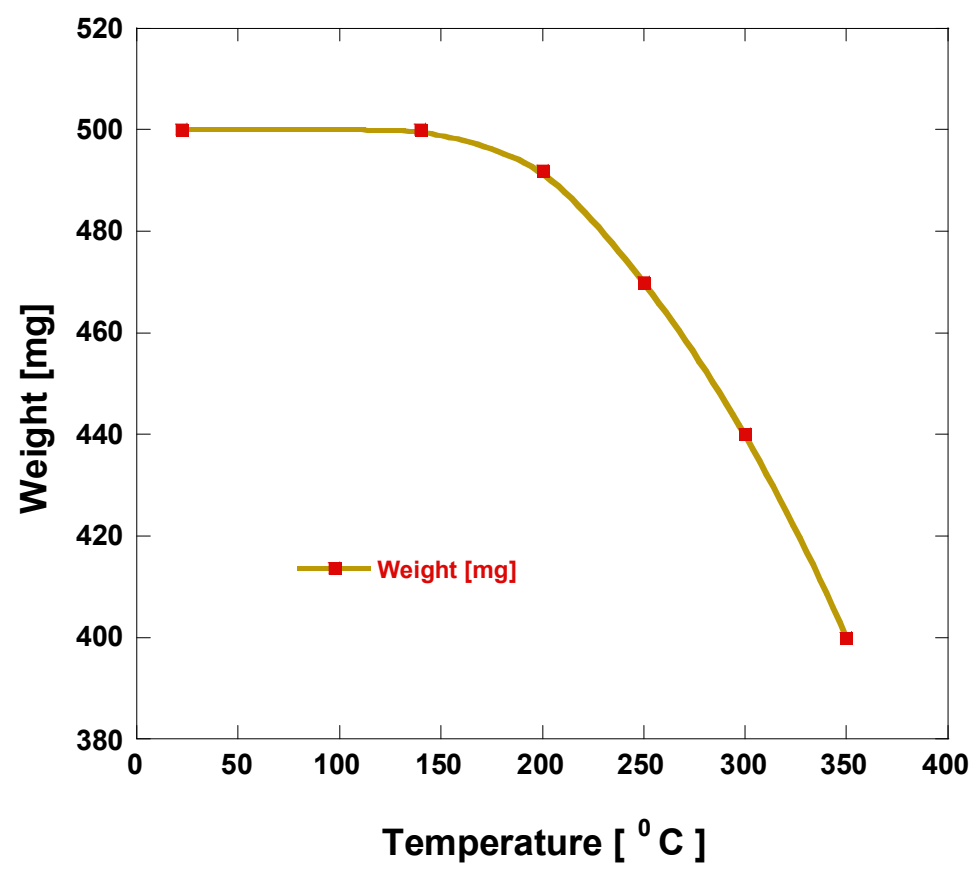

Figure 2. Temperature dependence of the weight of the heated samples.

However it is possible that parts of the same polymeric chain, or parts of different neighboring chains, adopt parallel local arrangement. Such structures behave like the crystalline planes when they are irradiated by $X$ rays, producing the diffraction phenomena. In the XRD spectrum each ordered domain, with the same inter-planar distance, gives a narrow diffraction peak. But in the polymeric materials these domains are characterized by very different inter-planar distance, giving diffraction peaks at different angles. The resulting spectrum is a superposition of the individual peaks giving a broad spectrum, [4]. For polymers the degree of ordering depends on synthesis process, but external factors as UV, X, gamma irradiation or heating process can affect the so called crystalline structure. In our case we were interested to observe possible modifications of the local ordering after heating. The samples were investigated before and after thermal treatment. The unheated polystyrene shows a broad and weak peak centred at $2 \theta=17.8^{\circ}$, (Fig.3). 


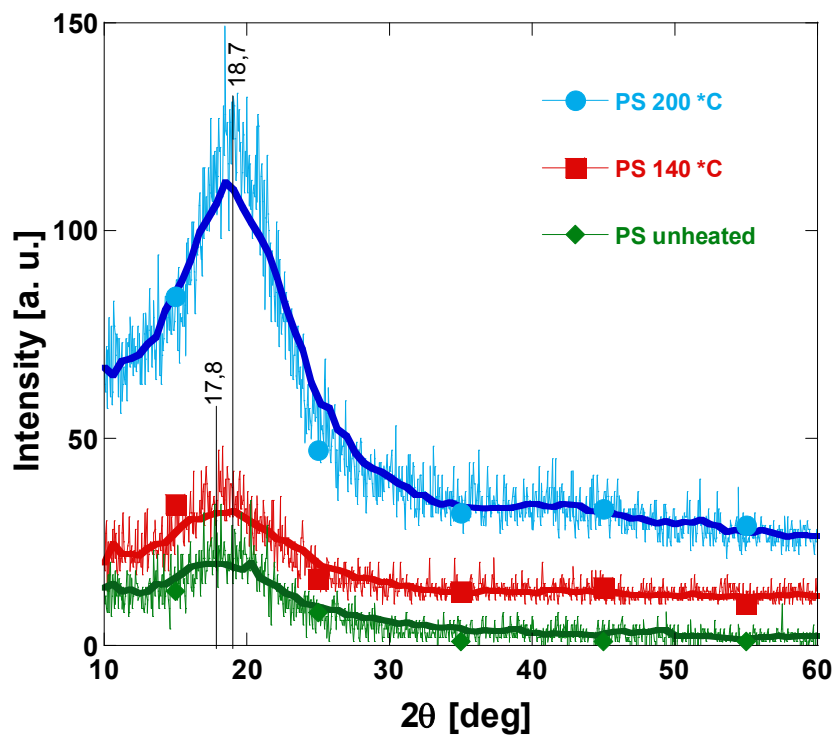

Figure 3. XRD patterns undegraded and, thermally degraded polystyrene at $140^{\circ} \mathrm{C}$ and $200{ }^{\circ} \mathrm{C}$.

From the diffraction theory we can calculate the inter-planar distance with the Bragg equation:

$$
d=\frac{k \cdot \lambda}{2 \sin \theta}
$$

where $k$ is the diffraction order and $2 \theta$ is the diffraction angle, [4]. We found the value $d=5.0 \AA$. The area $S$ under the diffraction peak is proportional with the concentration of the ordered domains in the sample and the width of the signal is correlated with the size of the ordered domains, [5]. Using Scherrer's formula we found the value $D=14.1 \AA$ of the size of ordered domains.

$$
D=\frac{K \cdot \lambda}{\beta \cdot \cos \theta}
$$

$D$ is the size of the ordered domains, $K=0.9$ is a proportionality factor and $\beta$ is the half line width. The sample heated at $140^{\circ} \mathrm{C}$ doesn't show major modifications; the shape and the amplitude of the diffraction peak are almost similar with those of the unheated sample. That shows that the thermal treatment below this temperature doesn't modify the local order of the polymer. Important changes appear at $200^{\circ} \mathrm{C}$. The amplitude of the peak and the area under the graphic increase compared with the unheated sample. The rapports of the areas is $R=3.80$ at $140^{\circ} \mathrm{C}$ and $R=4.20$ at $200^{\circ} \mathrm{C}$. 
The thermal treatment facilitates the local ordered arrangement of polymeric chains and the increase of ratio of the crystalline phase, [6-8]. It can be observed a weak shift towards higher diffraction angles of the main peak at $18.7^{0}$, (Fig. 3). The new inter-planar distance is $d=4.7 \AA$, shoving a more compact structure of the polymer. If the heating process is continued, above $200^{\circ} \mathrm{C}$, there is a decrease of the intensity and area of the diffraction peaks, (Fig. 4). This reduction is associated with the destruction of the ordered phase determined by the oxidation.

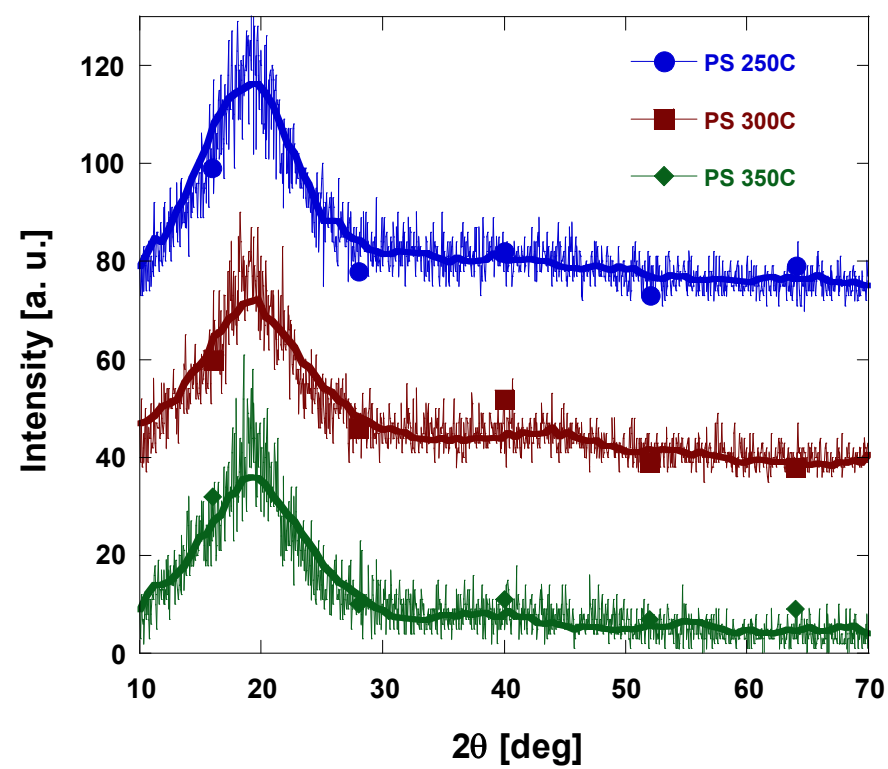

Figure 4. XRD patterns of unheated and thermally degraded polystyrene at $250^{\circ} \mathrm{C}, 300^{\circ} \mathrm{C}$ and $350^{\circ} \mathrm{C}$.

The modifications induced by thermal treatment were analyzed also by IR measurements. Usually the heating at moderate temperatures has small effects on the vibrations of the molecular bonds and on the IR spectrum. The IR spectra of polystyrene heated at different temperatures are shown in figure 5 . The most intense vibration bands can be observed at $1041 \mathrm{~cm}^{-1}$, $1232 \mathrm{~cm}^{-1}, 1485 \mathrm{~cm}^{-1}, 1600 \mathrm{~cm}^{-1}, 2854 \mathrm{~cm}^{-1}$ and $2926 \mathrm{~cm}^{-1}$. These bands are assigned as follows: the peak at $2926 \mathrm{~cm}^{-1}$ represents $\mathrm{H}-\mathrm{C}-\mathrm{H}$ asymmetric stretching vibration of chain backbone. The peak at $1600 \mathrm{~cm}^{-1}$ is associated to the phenyl ring stretching vibration of $\mathrm{C}=\mathrm{C}-\mathrm{C}$ conjugative system. 
The peak at $1485 \mathrm{~cm}^{-1}$ represents either out of plane or in plane $\mathrm{C}-\mathrm{H}$ bending vibration of the chain backbone. The peak at $1232 \mathrm{~cm}^{-1}$ is assigned to $\mathrm{C}-\mathrm{C}-\mathrm{O}-\mathrm{C}-\mathrm{C}$ stretching. The peak at $1041 \mathrm{~cm}^{-1}$ corresponds to phenyl in plane $\mathrm{C}-\mathrm{H}$ bending vibration, $[5,9,10,13]$. Low amplitude of the bands in the $1250 \mathrm{~cm}^{-1}$ range are in accord with other works reported in literature, [14]. The heating below $200^{\circ} \mathrm{C}$ doesn't have major effect on the shape, intensity and position of the vibration bands. At $200^{\circ} \mathrm{C}$ a new band appears at $896 \mathrm{~cm}^{-1}$, showing the apparition of a vibration determined by the crystallization of the sample.

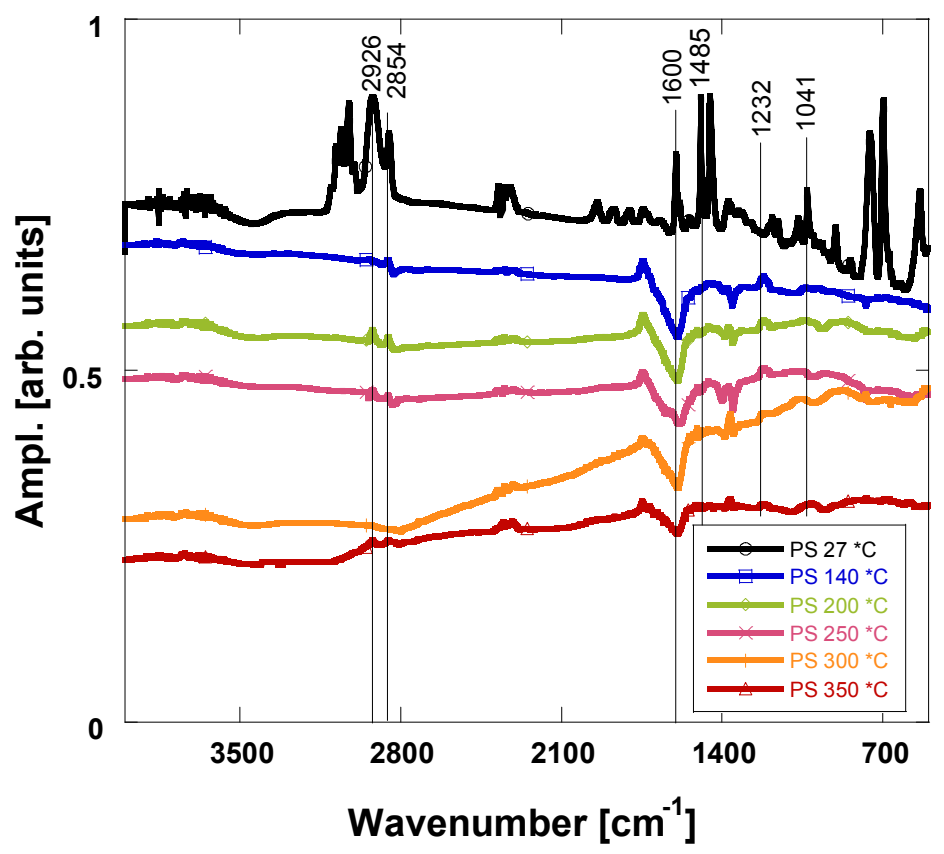

Figure 5. IR spectra of polystyrene at different temperatures between 27 ${ }^{\circ} \mathrm{C}$ and $350^{\circ} \mathrm{C}$

This observation is in accord with the XRD measurements, which indicate structural modification at high temperature. At $300^{\circ} \mathrm{C}$ the intensity of the majority of the vibration bands diminishes, $\left(1486 \mathrm{~cm}^{-1}, 2854 \mathrm{~cm}^{-1}\right.$ and $\left.2926 \mathrm{~cm}^{-1}\right)$. At $350^{\circ} \mathrm{C}$ the intensity of the vibration bands diminishes again and some bands almost vanish $\left(2854 \mathrm{~cm}^{-1}\right.$ and $\left.2926 \mathrm{~cm}^{-1}\right)$. 
XRD AND IR INVESTIGATIONS OF SOME COMMERCIAL POLYSTYRENE SAMPLES THERMALLY ...

\section{CONCLUSIONS}

Commercial polystyrene heated at different temperatures was investigated by $X R D$ and IR methods. $X R D$ investigation reveals some structural changes of heated samples. Heating up to $200^{\circ} \mathrm{C}$ facilitates the local arrangement of the polymeric chains in ordered structures. This is demonstrated by the increase of the intensity and the area of the diffraction peaks. The slight shift of the diffraction peak from $17.8^{\circ}$ to $18.7^{\circ}$ indicated the evolution of the polymeric chain towards a more compact structure. Heating above $200^{\circ} \mathrm{C}$ is followed by oxidation of the polymer and the reduction of the ordered structure.

The conclusions deducted from XRD investigation have been confirmed by IR measurements. At room temperature a very neat spectra is obtained. At $200^{\circ} \mathrm{C}$ a vibration band appears at $896 \mathrm{~cm}^{-1}$, determined by the crystallization of the sample. Above this temperature the intensity of the majority of the vibration bands diminishes, and some bands almost vanish. This behavior is associated to the oxidative process of the sample.

\section{EXPERIMENTAL SECTION}

Samples of commercial polystyrene, used as thermal insulation for building, were heated 30 minutes at different temperatures, $140^{\circ} \mathrm{C}, 200^{\circ} \mathrm{C}$, $250^{\circ} \mathrm{C}, 300^{\circ} \mathrm{C}$ and $350^{\circ} \mathrm{C}$ and then investigated by XRD and IR methods. XRD measurements were performed with Brucker X-ray diffractometer with $\mathrm{Cu} \mathrm{Ka}(\lambda=1.54 \mathrm{~nm})$ at $45 \mathrm{KV}$ and $40 \mathrm{~mA}$. The $2 \theta$ range of $10-60^{\circ}$ was recorded [11, 12]. The IR absorption spectra were recorded in $400-4000 \mathrm{~cm}^{-}$ ${ }^{1}$ spectral range with JASCO FTIR 4100 spectrometer.

The polystyrene was divided into 6 samples, each sample having 500 $\mathrm{mg}$ weigh. One sample has been studied separately in the initial state and the other 5 samples were heated at $140^{\circ} \mathrm{C}, 200^{\circ} \mathrm{C}, 250^{\circ} \mathrm{C}, 300^{\circ} \mathrm{C}, 350^{\circ} \mathrm{C}$ for 30 minutes. For some samples a variation of the mass and color with the temperature was observed, (Table 1).

Table 1. Variation of the properties of polystyrene samples upon heating.

\begin{tabular}{|c|c|c|c|c|}
\hline Samples & Initial weigh [mg] & Final weigh [mg] & Temperature $\left[{ }^{0} \mathrm{C}\right]$ & Color \\
\hline PS1 & 500 & 500 & 22 & White \\
\hline PS2 & 500 & 500 & 140 & White \\
\hline PS3 & 500 & 492 & 200 & White-gray \\
\hline PS4 & 500 & 470 & 250 & Gray \\
\hline PS5 & 500 & 440 & 300 & Black-gray \\
\hline PS6 & 500 & 400 & 350 & Black \\
\hline
\end{tabular}




\section{REFERENCES}

1. A. Martínez-Romo, R. González-Mota, J.J. Soto-Bernal, I. Rosales-Candel, Hindawi Publishing Corporation. Journal of Spectroscopy, 2015. Article ID: 586514.

2. M. Pop, S.Traian, L. Daraban, R. Fechete, Studia UBB Chemia, 2011, 56, 129.

3. J.P. Cohen, "Addad Physical properties of polymeric gels", Chichester (UK): John Wiley \& Sons, 1996.

4. Barbara Stuart, "Polymer Analysis". Chichester (UK), John Wiley \& Sons, 2002.

5. M. Todica, V. Simon, T. Stefan, D.L.Trandafir, I. Balasz, Indian Journal of Pure and Applied Physics, 2015 53, 359.

6. M. Todica, T. Stefan, S. Simion, I. Balasz, L. Daraban, Turkish Journal of Physics, 2014, 1.

7. M. Todica, M. Nagy, C. Niculaescu, O. Stan, C. Nicolae, C.V. Pop, Journal of Spectroscopy, 2016, Article ID: 9605312.

8. M. Todica, N. Cioica, L.E. Olar, I. Papuc, C. Cota, E. Marin, D. Manea, E.M. Nagy, Romanian Biotechnological Letters, 2016, Vol. 21, No. 5, 11825.

9. M. Todica, L. Udrescu, "Metode experimentale în fizica polimerilor", Presa Universitară Clujeană, 2013, 56.

10. H. Zhen-Li, L. Lie-Xiong, L. Hong, Z. Yuan-Di, Journal of Molecular Structure. 2005, 738, 155.

11. R. Hirian, S. Mican, O. Isnard, L. Barbu-Tudoran, V. Pop, Journal of Alloys and Compounds, 2017, 697, 19.

12. H. Mocuta, Marieta Mureşan-Pop, Irina Kacsó, G. Borodi, S. Simon, I. Bratu, Studia UBB Chemia, 2012, 57, 4, 135.

13. M.M. Radhi, A.J. Haider, Z.N. Jameel, T.W. Tee, M. Z.B. Rahman, A.B. Kassim, Research Journal of Chemical Sciences, 2012, 2(11), 1.

14. C.P. Ennis, R.I. Kaiser, Physical Chemistry Chemical Physics, 2010, 12, 45, 14884. 